\title{
Expression of stromal cell-derived factor-1 $\alpha$ is an independent risk factor for lymph node metastasis in early gastric cancer
}

\author{
IK-CHAN SONG $^{1 *}$, ZHE-LONG LIANG ${ }^{2 *}$, JUNG-CHAN LEE ${ }^{1}$, SONG-MEI HUANG $^{2}$, HA-YON KIM $^{1}$, \\ YOON-SUK OH ${ }^{1}$, HWAN-JUNG YUN ${ }^{1}$, JI-YOUNG SUL ${ }^{3}$, DEOG-YEON JO ${ }^{1}$, \\ SAMYONG KIM $^{1}$, JIN-MAN KIM ${ }^{2}$ and HYO-JIN LEE ${ }^{1}$ \\ ${ }^{1}$ Department of Internal Medicine, Cancer Research Institute, and Daejeon Regional Cancer Center, \\ Chungnam National University Hospital; ${ }^{2}$ Department of Pathology, Cancer Research Institute, \\ Daejeon Regional Cancer Center, Infection Signaling Network Research Center, \\ and Chungnam National Univerisity School of Medicine; ${ }^{3}$ Department of General Surgery, \\ Chungnam National University School of Medicine, Daejeon, Republic of Korea
}

Received March 14, 2011; Accepted August 15, 2011

DOI: $10.3892 / 01.2011 .389$

\begin{abstract}
Lymph node metastasis is considered to be a significant prognostic factor for early gastric cancer (EGC). However, no real consensus exists on which patient and/ or tumor characteristics are associated with lymph node metastasis. We investigated whether stromal cell-derived factor (SDF)-1 $\alpha$ expression correlates with lymph node metastasis in patients with EGC by immunohistochemically examining the expression of SDF- $1 \alpha$ in 138 archival tissue specimens of EGC. Of these specimens, 59 (42.8\%) and 79 (57.2\%) were grouped into SDF- $1 \alpha$-positive and SDF- $1 \alpha$-negative groups, respectively. No significant differences existed with respect to age, gender, tumor location, proportion of tumors $>20 \mathrm{~mm}$ in size, macroscopic type, depth of invasion or histology between the SDF-1 $\alpha$-positive and -negative groups. However, the SDF- $1 \alpha$-positive group was significantly correlated with lymphovascular invasion and lymph node metastasis. Results of the univariate analyses indicated that lymphovascular invasion, undifferentiated histology and SDF-1 $\alpha$ positivity were statistically significant risk factors affecting lymph node metastasis in patients with EGC. Multivariate analyses showed that lymphovascular invasion [hazard ratio (HR), 8.595; 95\% confidence interval (CI), 1.694-43.595; $\mathrm{P}=0.009]$, undifferentiated histology (HR, 2.965; 95\% CI, 1.037-8.471; $\mathrm{P}=0.043)$ and SDF- $1 \alpha$ positivity (HR, 2.108; 95\% CI, 1.316 $10.135 ; \mathrm{P}=0.013$ ) were independent risk factors predicting lymph node metastasis in EGC. In conclusion, these results
\end{abstract}

Correspondence to: Dr Hyo Jin Lee, Department of Internal Medicine, Chungnam National University Hospital, 640 Daesa-dong, Jung-gu, Daejeon, Republic of Korea

E-mail: cymed@cnu.ac.kr

${ }^{*}$ Contributed equally

Key words: SDF-1 $\alpha$, early gastric cancer, lymph node metastasis suggest that SDF-1 $\alpha$ expression in tumor cells is a predictive marker of lymph node metastasis in EGC.

\section{Introduction}

Early gastric cancer (EGC) is defined as adenocarcinoma localized to the mucosa or the submucosa, irrespective of lymph node metastasis (1). The incidence of EGC has increased due to mass screening and advances in diagnostic technology. In Korea, EGC increased from $29 \%$ in 1995 to $33 \%$ in 1999 . This trend was more prominent in Japan, where EGC represents more than $50 \%$ of all gastric cancers (2-4). While the prognosis for surgically treated EGC is generally excellent, with five-year survival greater than $90 \%$, patients with lymph node metastasis have lower survival rates than those without metastasis (4-8). Accurate prediction of lymph node involvement is of crucial significance for appropriate curative treatment planning. Lymph node-negative EGC patients may be curatively treated with minimally invasive endoscopic mucosal resection or endoscopic submucosal dissection, whereas lymph nodepositive patients should undergo gastrectomy with lymph node dissection (9-11). Gastrectomy is associated with a high morbidity and mortality, and postoperative quality of life may be impaired by weight loss, loss of appetite and other metabolic and nutritional changes. This aggressive surgical approach should be reserved only for EGC patients at high risk of lymph node metastasis (9). Therefore, clarification of the biological features of EGC with lymph node metastasis may aid in the identification of a high-risk group of patients, and assist in planning a strategy for their treatment.

Stromal cell-derived factor (SDF)-1 $\alpha$, also known as CXCL12, is a small, cytokine-like protein that regulates leukocyte trafficking to appropriate organs and maintains normal immune system function. However, in addition to its role in the immune system, it is now clear that SDF-1 $\alpha$ is expressed in a number of distinct types of normal and cancerous tissues, and that SDF-1 $\alpha$ has significant functions in development, proliferation, angiogenesis and motility $(12,13)$. It has also 

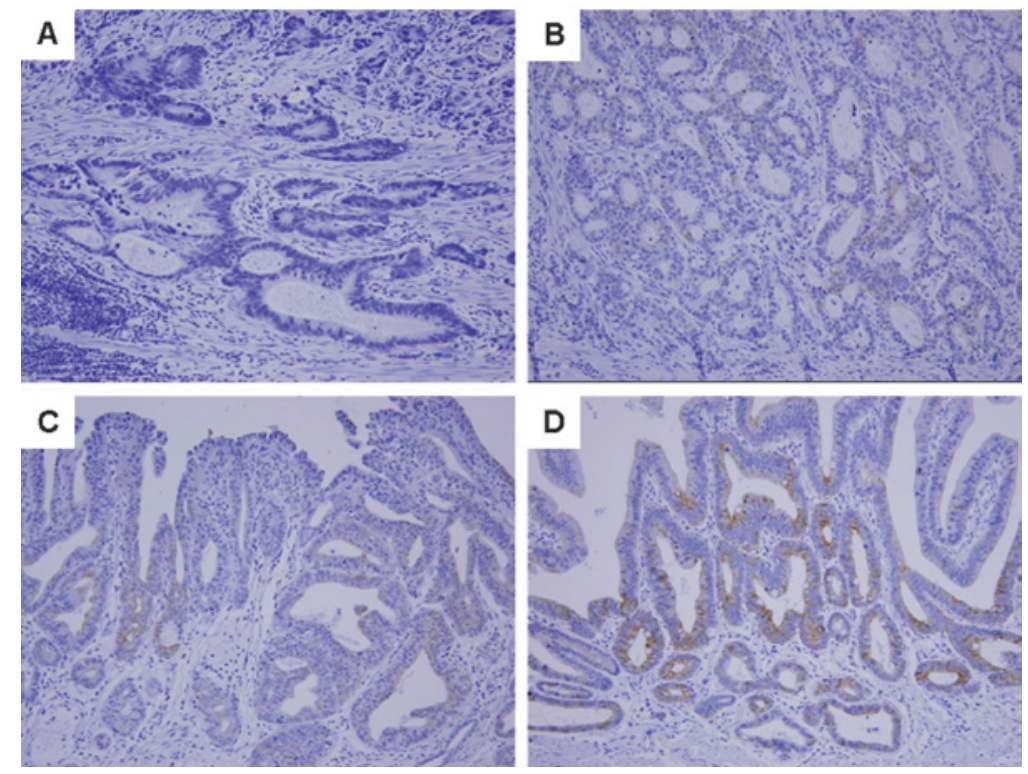

Figure 1. Representative photomicrographs of SDF-1 $\alpha$ immunohistochemical staining in early gastric cancer tissues. (A) No staining intensity. (B-D) Weak, intermediate and strong staining intensity, respectively (magnification, x200).

been reported that this chemokine and its receptor, CXCR4, are involved in tumor progression and metastasis (13-16). In the case of gastric cancer, SDF-1 $\alpha$ expression in primary cancers was reported to be an independent prognostic factor among patients with cancers at various stages, suggesting a role as a biological marker $(17,18)$. Thus, it is possible that there may be a correlation between SDF- $1 \alpha$ expression and lymph node metastasis in patients with EGC.

\section{Patients and methods}

Patients and tumor samples. This study used tissue samples from 138 consecutive patients with EGC undergoing surgical resection at Chungnam National University Hospital, Daejeon, Korea, between 2001 and 2003. The patients had histologically confirmed adenocarcinoma of the stomach. All patients signed informed consent for therapy as well as for subsequent tissue studies, which had received prior approval by an institutional review board. Clinicopathological characteristics at the time of surgery were assessed using the general rules established by the Japanese Gastric Cancer Association (19).

Immunohistochemical staining of SDF-1 $\alpha$. Immunohistochemical staining was performed using a monoclonal anti-SDF- $1 \alpha$ antibody (MAB350; R\&D Systems, Minneapolis, MN, USA) and the EnVision-HRP detection system (DakoCytomation, Carpinteria, CA, USA) according to the manufacturer's instructions. Sections $(3 \mu \mathrm{m})$ were cut from gastric cancer tissue microarray blocks, mounted on slides treated with 3-aminopropyltriethoxysilane (APES, Sigma Chemical, St. Louis, MO, USA) and dried for $2 \mathrm{~h}$ at $56^{\circ} \mathrm{C}$ prior to staining. The sections were deparaffinized in xylene and rehydrated in a graded alcohol series. Following antigen retrieval by heating under pressure in citrate buffer $(\mathrm{pH} 6.0)$ for 3 min, tissue sections were treated with $3 \%$ hydrogen peroxide for $10 \mathrm{~min}$ to block endogenous peroxidases. The sections were then incubated for $30 \mathrm{~min}$ in a humid chamber at room temperature with the anti-SDF-1 $\alpha$ antibody (1:50) diluted in a background-reducing diluent (S0809; DakoCytomation). Slides were then incubated with EnVision reagent for $30 \mathrm{~min}$, followed by 3,3'-diaminobenzidine (DAB) chromogen for 5 min, counterstained with Mayer's hematoxylin and mounted. Exclusion of the primary antibody during immunostaining was used in the negative controls, while lymphocytes of normal spleen sections served as positive controls. Immunostaining was evaluated independently by two of the authors, who were blinded to each patient's clinicopathological findings. Tumors were classified into four grades according to staining intensity (grade 0 , no staining; grade 1, weak staining intensity; grade 2, moderate staining intensity; grade 3 , strong staining intensity). In the case of heterogeneous sample staining, the higher score was selected if more than $50 \%$ of the cells exhibited a higher intensity of staining.

Statistical analysis. The association of SDF- $1 \alpha$ expression with clinicopathological characteristics was assessed using the Pearson's $\chi^{2}$ test or linear-by-linear associations. For analysis of the factors responsible for lymph node metastasis, a logistic regression analysis was used. $\mathrm{P}<0.05$ was considered to be statistically significant. Statistical analyses were conducted using SPSS 13.0 (SPSS, Chicago, IL, USA).

\section{Results}

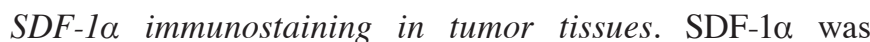
detected in the cytoplasm and cellular membrane of gastric cancer cells. SDF-1 $\alpha$ expression was variable [no staining, 79 patients (57.2\%); weak staining, 30 (21.7\%); moderate staining, 17 (12.3\%); and strong staining, 12 patients (8.7\%); Fig. 1]. The patients were divided into two groups according to SDF-1 $\alpha$ expression; the SDF-1 $\alpha$-positive group $(n=59)$ was defined as patients with weak to strong SDF-1 $\alpha$ expression, and the SDF- $1 \alpha$-negative group $(n=79)$ was defined as patients with no SDF-1 $\alpha$ expression. 
Table I. Clinicopathological characteristics according to SDF-1 $\alpha$ expression.

\begin{tabular}{|c|c|c|c|c|}
\hline \multirow[b]{2}{*}{ Variable } & \multirow{2}{*}{$\begin{array}{c}\text { Total } \\
\mathrm{n}=138\end{array}$} & \multicolumn{2}{|c|}{ SDF- $1 \alpha$} & \multirow[b]{2}{*}{ P-value } \\
\hline & & Positive $\mathrm{n}=59(\%)$ & Negative $\mathrm{n}=79(\%)$ & \\
\hline Age (years) & & & & $0.342^{\mathrm{a}}$ \\
\hline$\leq 65$ & 96 & $38(64.4)$ & $58(73.4)$ & \\
\hline$>65$ & 42 & $21(35.6)$ & $21(26.6)$ & \\
\hline Gender & & & & $0.544^{\mathrm{a}}$ \\
\hline Male & 98 & $44(74.6)$ & $54(68.4)$ & \\
\hline Female & 40 & $15(25.4)$ & $25(31.6)$ & \\
\hline Tumor location & & & & $0.672^{\mathrm{b}}$ \\
\hline Upper & 4 & $1(1.7)$ & $3(3.8)$ & \\
\hline Middle & 77 & $33(55.9)$ & $44(55.7)$ & \\
\hline Lower & 57 & $25(42.4)$ & $32(40.5)$ & \\
\hline Tumor size (mm) & & & & $0.688^{a}$ \\
\hline$\leq 20$ & 50 & $23(39.0)$ & $27(34.2)$ & \\
\hline$>20$ & 88 & $36(61.0)$ & $52(65.8)$ & \\
\hline Macroscopic types & & & & $0.280^{\mathrm{b}}$ \\
\hline Elevated & 18 & $11(18.6)$ & $7(8.9)$ & \\
\hline Flat & 12 & $5(8.5)$ & $7(8.9)$ & \\
\hline Depressed & 95 & $36(61.0)$ & $59(74.7)$ & \\
\hline Mixed & 13 & 7 (11.9) & $6(7.6)$ & \\
\hline Depth of invasion & & & & $0.497^{\mathrm{a}}$ \\
\hline Mucosal & 9 & $5(8.5)$ & $4(5.1)$ & \\
\hline Submucosal & 129 & $54(91.5)$ & $75(94.9)$ & \\
\hline Lymphovascular invasion & & & & $0.042^{\mathrm{a}}$ \\
\hline Negative & 52 & $16(27.1)$ & $36(45.6)$ & \\
\hline Positive & 86 & $43(72.9)$ & $43(54.4)$ & \\
\hline Histology & & & & $0.761^{\mathrm{a}}$ \\
\hline Differentiated & 81 & $36(61.0)$ & $45(57.0)$ & \\
\hline Undifferentiated & 57 & $23(39.0)$ & $34(43.0)$ & \\
\hline Lymph node metastasis & & & & $0.018^{\mathrm{a}}$ \\
\hline Negative & 110 & $41(69.5)$ & $69(87.3)$ & \\
\hline Positive & 28 & $18(30.5)$ & $10(12.7)$ & \\
\hline
\end{tabular}

${ }^{\text {aP }}$-values were calculated by pairwise comparisons from the Pearson's $\chi^{2}$ test. ${ }^{b} \mathrm{P}$-values were calculated by comparisons of three or four groups from linear-by-linear associations.

Association between SDF-1 $\alpha$ expression and clinicopathological factors. The correlation of SDF-1 $\alpha$ expression and clinicopathological characteristics is shown in Table I. No significant differences existed with respect to age, gender, tumor location, proportion of tumors $>20 \mathrm{~mm}$ in size, macroscopic type, depth of invasion or histology between SDF-1 $\alpha$-positive and -negative groups. However, the SDF-1 $\alpha$-positive group was significantly correlated with lymphovascular invasion $(\mathrm{P}=0.042)$ and with lymph node metastasis $(\mathrm{P}=0.018)$.

SDF-1 $\alpha$ expression and lymph node metastasis. To estimate the clinical significance of various clinicopathological factors that may affect lymph node metastasis in EGC, univariate analyses were performed. As shown in Table II, lymphovascular invasion [hazard ratio (HR), 10.833; 95\% confidence interval (CI), 2.450-47.895; $\mathrm{P}=0.002$ ], undifferentiated histology (HR, 3.277;
95\% CI, 1.378-7.791; $\mathrm{P}=0.007)$ and $\mathrm{SDF}-1 \alpha$ positivity (HR, 3.029; 95\% CI, 1.276-7.189; $\mathrm{P}=0.012$ ) were statistically significant risk factors affecting lymph node metastasis in patients with EGC. To determine the independent prognostic effects of these variables, multivariate analyses were performed using logistic regression analysis. The results again demonstrated that lymphovascular invasion (HR, 8.595; 95\% CI, 1.69443.595; $\mathrm{P}=0.009)$, undifferentiated histology ( $\mathrm{HR}, 2.965 ; 95 \%$ $\mathrm{CI}, 1.037-8.471 ; \mathrm{P}=0.043$ ) and $\mathrm{SDF}-1 \alpha$ positivity (HR, 2.108; 95\% CI, 1.316-10.135; $\mathrm{P}=0.013$ ) were independent risk factors predicting lymph node metastasis in EGC patients (Table III).

\section{Discussion}

The prognosis for EGC is favorable following radical surgery. Lymph node metastasis is considered to be a significant prog- 
Table II. Univariate analysis of risk factors for lymph node metastasis in patients with early gastric cancer.

\begin{tabular}{lccr}
\hline Variables & Hazard ratio & 95\% Confidence interval & P-value \\
\hline Age (> 65 years) & 1.354 & $0.564-3.251$ & 0.497 \\
Females & 1.207 & $0.493-2.955$ & 0.680 \\
Tumor location (lower) & 1.083 & $0.468-2.508$ & 0.852 \\
Tumor size (>20 mm) & 2.444 & $0.917-6.513$ & 0.074 \\
Macroscopic type & 1.857 & $0.590-5.843$ & 0.290 \\
(Depressed or mixed) & & & $0.254-17.672$ \\
Depth of invasion & 2.118 & & 0.488 \\
(Submucosal) & & $2.450-47.895$ & \\
Lymphovascular invasion & 10.833 & $1.378-7.791$ \\
(Positive) & & & 0.002 \\
Histology & 3.277 & $1.276-7.189$ \\
(Undifferentiated) & 3.029 & & 0.007 \\
SDF-1 $\alpha$ expression & & & 0.012 \\
(Positive) & & & \\
\hline
\end{tabular}

Table III. Multivariate analysis of risk factors for lymph node metastasis in patients with early gastric cancer.

\begin{tabular}{lccc}
\hline Variables & Hazard ratio & 95\% Confidence interval & P-value \\
\hline Age (> 65 years) & 1.524 & $0.550-4.225$ & 0.418 \\
Females & 1.520 & $0.540-4.277$ & 0.428 \\
Tumor location (lower) & 1.366 & $0.504-3.703$ & 1.366 \\
Tumor size (>20 mm) & 2.314 & $0.742-7.216$ & 2.314 \\
Macroscopic type & 2.108 & $0.566-7.857$ & \\
(Depressed or mixed) & & $0.062-21.939$ \\
$\begin{array}{l}\text { Depth of invasion } \\
\text { (Submucosal) }\end{array}$ & 1.163 & & \\
Lymphovascular invasion & 8.595 & $1.694-43.595$ \\
(Positive) & & $1.037-8.471$ \\
$\begin{array}{l}\text { Histology } \\
\text { (Undifferentiated) }\end{array}$ & 2.965 & & 0.920 \\
$\begin{array}{l}\text { SDF-1 } \alpha \text { expression } \\
\text { (Positive) }\end{array}$ & 2.108 & $1.316-10.135$ \\
\hline
\end{tabular}

nostic factor for EGC as the 5-year survival rate of patients without lymph node metastasis is approximately $95 \%$, whereas that of patients with metastasis is approximately $83 \%(7,20)$. Therefore, a number of studies have been conducted to identify predictive parameters, particularly biological markers, of lymph node metastasis in EGC. We report for the first time that SDF-1 $\alpha$ expression in tumor cells is an independent risk factor for lymph node metastasis in EGC. However, there remains no real consensus on which patient and/or tumor characteristics are associated with lymph node metastasis (9,21-23).

Recently, certain reports have demonstrated that SDF- $1 \alpha$ expression is associated with the progression and metastasis of a number of types of cancer, including malignant glioma, esophageal carcinoma, non-small cell lung cancer and colorectal cancer (24-29). In gastric cancer, Ishigami et al reported that $\mathrm{SDF}-1 \alpha$ expression was significantly associated with lymph node metastasis, depth of invasion, lymphatic invasion, tumor diameter and higher stage. In addition, the SDF- $1 \alpha$-positive group showed significantly poorer surgical outcomes than the SDF-1 $\alpha$-negative group, suggesting SDF-1 $\alpha$ to be an independent prognostic factor in gastric cancer (17). Iwasa et al also showed that SDF-1 $\alpha$ expression was significantly correlated with lymphovascular invasion and lymph node and liver metastasis in patients with intestinal-type gastric cancer (18). These findings led to speculation that SDF-1 $\alpha$ is a predictive marker of lymph node metastasis in EGC.

In this study, it was found that SDF- $1 \alpha$ expression in EGC was significantly associated with lymphovascular invasion and lymph node metastasis, whereas SDF-1 $\alpha$ expression was 
not associated with age, gender, tumor location, tumor size, macroscopic type, depth of invasion or histology (Table I). Results of the univariate analyses of risk factors for lymph node metastasis showed that lymphovascular invasion, undifferentiated histology and SDF-1 $\alpha$ expression are risk factors in patients with EGC (Table II). Furthermore, multivariate analyses clearly indicated that SDF- $1 \alpha$ expression is as much an independent risk factor for lymph node metastasis as is lymphovascular invasion or undifferentiated histology. These data suggest that SDF-1 $\alpha$ expression in tumor cells is a useful marker for the prediction of lymph node metastasis in patients with EGC.

The mechanism by which SDF-1 $\alpha$ contributes to gastric cancer progression events, including lymph node metastasis, remains unclear. One potential explanation is that SDF-1 $\alpha$ is involved in tumor progression in an autocrine and/or paracrine manner. The concomitant expression of SDF-1 $\alpha$ and its receptor, CXCR4, in the same brain tumor cells has been characterized as an autocrine and/or paracrine mechanism of cancer cell stimulation, resulting in more aggressive behavior $(30,31)$. Subsequently, the autocrine/paracrine mitogenic activity of SDF-1 $\alpha$ was reported in cell lines and primary cell cultures of human glioblastoma multiforme $(32,33)$. Barbieri et al also reported that the overexpression of SDF-1 $\alpha$ promoted autocrine/paracrine cell proliferation in human pituitary tumor cells (30). Another possible mechanism is that SDF-1 $\alpha$ may promote tumor angiogenesis by attracting endothelial cells to the tumor microenvironment. Pathologically induced SDF-1 $\alpha$ secretion by brain tumor cells increases the recruitment of circulating endothelial progenitors (34). Furthermore, inhibition of the SDF-1 $\alpha /$ CXCR4 receptor pathway reduced short-term homing and long-term engraftment of vascular progenitors, and decreased the growth of gastrointestinal tumors through the suppression of angiogenesis $(35,36)$.

In conclusion, this study has demonstrated that the tumor expression of SDF-1 $\alpha$ is an independent risk factor for lymph node metastasis in patients with EGC, suggesting that SDF-1 $\alpha$ is a useful predictive marker. Further studies are required to elucidate the mechanisms linking SDF-1 $\alpha$ secreted by tumor cells to gastric cancer.

\section{Acknowledgements}

This study was supported in part by the Basic Science Research Program through the National Research Foundation of Korea (NRF) funded by the Ministry of Education, Science and Technology (NRF-2009-0076540) and the National Research Foundation of Korea grant funded by the Korean government (MEST) (No. 2011-0006229).

\section{References}

1. Okamura T, Tsujitani S, Korenaga D, Haraguchi M, Baba H, Hiramoto $\mathrm{Y}$ and Sugimachi K: Lymphadenectomy for cure in patients with early gastric cancer and lymph node metastasis. Am J Surg 155: 476-480, 1988.

2. Park YD, Chung YJ, Chung HY, et al: Factors related to lymph node metastasis and the feasibility of endoscopic mucosal resection for treating poorly differentiated adenocarcinoma of the stomach. Endoscopy 40: 7-10, 2008.

3. Isozaki H, Tanaka N and Okajima K: General and specific prognostic factors of early gastric carcinoma treated with curative surgery. Hepatogastroenterology $46: 1800-1808,1999$.
4. Maehara Y, Orita H, Okuyama T, Moriguchi S, Tsujitani S, Korenaga D and Sugimachi K: Predictors of lymph node metastasis in early gastric cancer. Br J Surg 79: 245-247, 1992.

5. Folli S, Dente M, Dell'Amore D, Gaudio M, Nanni O, Saragoni L and Vio A: Early gastric cancer: prognostic factors in 223 patients. Br J Surg 82: 952-956, 1995.

6. Kitamura K, Yamaguchi T, Taniguchi H, Hagiwara A, Sawai K and Takahashi T: Analysis of lymph node metastasis in early gastric cancer: rationale of limited surgery. J Surg Oncol 64: 42-47, 1997

7. Habu H, Takeshita K, Sunagawa M and Endo M: Lymph node metastasis in early gastric cancer. Int Surg 71: 244-247, 1986.

8. Folli S, Morgagni P, Roviello F, et al: Italian Research Group for Gastric Cancer (IRGGC), Risk factors for lymph node metastases and their prognostic significance in early gastric cancer (EGC) for the Italian Research Group for Gastric Cancer (IRGGC). Jpn J Clin Oncol 31: 495-499, 2001.

9. Kwee RM and Kwee TC: Predicting lymph node status in early gastric cancer. Gastric Cancer 11: 134-148, 2008.

10. Brennan MF: Current status of surgery for gastric cancer: a review. Gastric Cancer 8: 64-70, 2005.

11. Nakajima T: Gastric cancer treatment guidelines in Japan. Gastric Cancer 5: 1-5, 2002.

12. Krop IE: Chemokine signaling in gliomas: prognostic factor, therapeutic target or both? Cancer Biol Ther 5: 1039-1041, 2006

13. Burger JA and Kipps TJ: CXCR4: a key receptor in the crosstalk between tumor cells and their microenvironment. Blood 107: 1761-1767, 2006.

14. Arya M, Patel HR and Williamson M: Chemokines: key players in cancer. Curr Med Res Opin 19: 557-564, 2003.

15. Scotton CJ, Wilson JL, Scott K, et al: Multiple actions of the chemokine CXCL12 on epithelial tumor cells in human ovarian cancer. Cancer Res 62: 5930-5938, 2002.

16. Koshiba T, Hosotani R, Miyamoto Y, et al: Expression of stromal cell-derived factor 1 and CXCR4 ligand receptor system in pancreatic cancer: a possible role for tumor progression. Clin Cancer Res 6: 3530-3535, 2000.

17. Ishigami $\mathrm{S}$, Natsugoe $\mathrm{S}$, Okumura $\mathrm{H}$, et al: Clinical implication of CXCL12 expression in gastric cancer. Ann Surg Oncol 14: 3154-3158, 2007.

18. Iwasa S, Yanagawa T, Fan J and Katoh R: Expression of CXCR4 and its ligand SDF-1 in intestinal-type gastric cancer is associated with lymph node and liver metastasis. Anticancer Res 29: 4751-4758, 2009

19. Japanese Gastric Cancer Association: Japanese classification of gastric carcinoma - 2nd English edition. Gastric Cancer 1: 10-24, 1998.

20. Li C, Kim S, Lai JF, et al: Risk factors for lymph node metastasis in undifferentiated early gastric cancer. Ann Surg Oncol 15: 1464-1469, 2008.

21. Kanai T, Konno H, Maruyama K, et al: p53 overexpression and proliferative activity do not correlate with lymph node metastasis in early gastric cancer. Eur Surg Res 29: 35-41, 1997.

22. Kabashima A, Maehara Y, Kakeji Y, Baba H, Koga T and Sugimachi K: Clinicopathological features and overexpression of matrix metalloproteinases in intramucosal gastric carcinoma with lymph node metastasis. Clin Cancer Res 6: 3581-3584, 2000.

23. Yonemura Y, Ninomiya I, Ohoyama S, et al: Correlation of c-erbB-2 protein expression and lymph node status in early gastric cancer. Oncology 49: 363-367, 1992.

24. Salmaggi A, Gelati M, Pollo B, et al: CXCL12 expression is predictive of a shorter time to tumor progression in low-grade glioma: a single-institution study in 50 patients. J Neurooncol 74: 287-293, 2005

25. Calatozzolo C, Maderna E, Pollo B, et al: Prognostic value of CXCL12 expression in 40 low-grade oligodendrogliomas and oligoastrocytomas. Cancer Biol Ther 5: 827-832, 2006.

26. Sasaki K, Natsugoe S, Ishigami S, et al: Expression of CXCL12 and its receptor CXCR4 correlates with lymph node metastasis in submucosal esophageal cancer. J Surg Oncol 97: 397-402, 2008.

27. Sasaki K, Natsugoe S, Ishigami S, et al: Expression of CXCL12 and its receptor CXCR4 in esophageal squamous cell carcinoma. Oncol Rep 21: 65-71, 2009.

28. Wagner PL, Hyjek E, Vazquez MF, et al: CXCL12 and CXCR4 in adenocarcinoma of the lung: association with metastasis and survival. J Thorac Cardiovasc Surg 137: 615-621, 2009.

29. Yoshitake N, Fukui H, Yamagishi $\mathrm{H}$, et al: Expression of SDF-1 $\alpha$ and nuclear CXCR4 predicts lymph node metastasis in colorectal cancer. Br J Cancer 98: 1682-1689, 2008. 
30. Barbieri F, Bajetto A, Stumm R, et al: Overexpression of stromal cell-derived factor 1 and its receptor CXCR4 induces autocrine/ paracrine cell proliferation in human pituitary adenomas. Clin Cancer Res 14: 5022-5032, 2008.

31. Rempel SA, Dudas S, Ge S and Gutiérrez JA: Identification and localization of the cytokine SDF1 and its receptor, CXC chemokine receptor 4 , to regions of necrosis and angiogenesis in human glioblastoma. Clin Cancer Res 6: 102-111, 2000

32. Bajetto A, Barbieri F, Dorcaratto A, et al: Expression of CXC chemokine receptors $1-5$ and their ligands in human glioma tissues: role of CXCR4 and SDF1 in glioma cell proliferation and migration. Neurochem Int 49: 423-432, 2006.

33. Barbero S, Bonavia R, Bajetto A, et al: Stromal cell-derived factor $1 \alpha$ stimulates human glioblastoma cell growth through the activation of both extracellular signal-regulated kinases $1 / 2$ and Akt. Cancer Res 63: 1969-1974, 2003.
34. Li M and Ransohoff RM: The roles of chemokine CXCL12 in embryonic and brain tumor angiogenesis. Semin Cancer Biol 19: 111-115, 2009.

35. Guleng B, Tateishi K, Ohta M, et al: Blockade of the stromal cell-derived factor-1/CXCR4 axis attenuates in vivo tumor growth by inhibiting angiogenesis in a vascular endothelial growth factor-independent manner. Cancer Res 65: 5864-5871, 2005.

36. Orimo A, Gupta PB, Sgroi DC, et al: Stromal fibroblasts present in invasive human breast carcinomas promote tumor growth and angiogenesis through elevated SDF-1/CXCL12 secretion. Cell 121: 335-348, 2005. 